\title{
Supports for households with children
}

\author{
IVICA URBAN, Institute of Public Finance
}

\section{INTRODUGTION}

The government allocates substantial funding for benefits intended for households with children. The aim of these benefits is to alleviate the risk of poverty for households with children, to reduce the gap in the standard of living between households with and without children, but also to encourage citizens to have more children.

The best known benefits are the child benefit, maternity and parental benefits and a lump-sum birth grant. Furthermore, a portion of the guaranteed minimum benefit is intended for support of children. However, financial support to households is implemented not only through social benefits but also through tax reliefs. The personal income tax (PIT) system thus contains a personal tax allowance for children whereby a taxpayer supporting one or more children has their tax liability reduced.

This paper deals with child benefit, the portion of the guaranteed minimum benefit intended for children and PIT personal tax allowance for children. The amounts of these supports depend on household income, i.e. supports are functions of income. Once these functions are calculated for hypothetical households and their graphs plotted, interesting interdependencies, patterns and irregularities can be noticed in certain supports but also in the set of supports viewed as a whole.

The key problem of this set of supports for children lies in the "stepwise" design of the child benefit which creates a situation where a minor change in income leads to major changes in the amount of the child benefit. If a household's income is only one HRK above a certain level, the benefit may be reduced for up to several hundred HRK. Such "jumps" should be reduced or removed altogether; this paper offers, as an illustration, an example reform achieving this goal.

\section{SUPPORT GALGULATION MODEL}

The supports of children amounts are calculated for hypothetical households differentiated by their membership structure and net income levels. Two sets of households were analyzed: (a) type A households - with two adults and two children, and (b) type B households - with two adults and three children. 
The adult members of a household are the mother and the father, while the children are of the

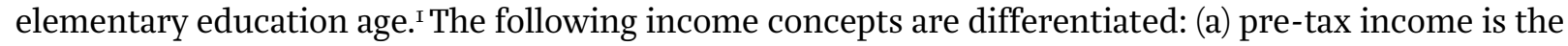
income subject to PIT; (b) after-tax income or net income is equal to the pre-tax income minus the PIT and the local surtax; (c) net household income is the sum of net incomes of all the household's members; (d) disposable household income is the sum of the net household income, the guaranteed minimum benefit and the child benefit. Net income per household member (NIHM) is the net household income divided by the number of members in the household. The two adult members of the household are taken to have the same pre-tax income and to share the personal tax allowance for children equally. The threeband general tax schedule (12, 25 and $40 \%$ ) is being applied. The surtax rate is $12 \%$. All the households are situated outside of areas of special state concern.

\section{GUARANTEED MINIMUM BENEFIT}

Guaranteed minimum benefit (GMB) is the basic social benefit intended for poverty alleviation. ${ }^{2}$ Eligible households are determined by income and assets testing.

In order to calculate the GMB amount due to a certain household, the "base" benefit amount, dependent on the number and characteristics of the household's members, needs to be calculated first. In a household with two adult members, each adult is eligible for HRK 480 , while each child is eligible for HRK 32O. Thus, the base amount for type A households is HRK I,600 $(2 \times 480+2 \times 320)$. Table I presents the base amounts for the most frequent household types.

\section{Table I}

"Base amounts" of the Guaranteed minimum benefit for certain types of households (in HRK)

\begin{tabular}{lcc} 
Household structure & GMB base amount \\
\hline One adult member & 800 \\
\hline One adult and one child & $\mathrm{I,I2O}$ \\
\hline Two adults & 960 \\
\hline Two adults and one child & $\mathrm{I}, 28 \mathrm{O}$ \\
\hline Two adults and two children & $\mathrm{I}, 600$ \\
\hline Two adults and three children
\end{tabular}

Source: author's calculation

In order to calculate the GMB amount, the net household income needs to be subtracted from the base amount. In the example under consideration, if the net household income equals zero, GMB amounts to HRK I,600, i.e. equals the base amount. If the net income equals HRK I,OOO, GMB amounts to HRK 6oo. Finally, if the net income amounts to HRK I,60o or more, GMB equals zero.

In this section of the analysis, it is not the whole GMB amount which is under consideration, but only the portion intended for children. Type A households with no net income receive GMB in the amount of HRK I,60O, with HRK 640, or $40 \%$ of the total amount, earmarked for children. The maximum GMB amount which a type B household may receive is HRK I,92O and the portion of it intended for children amounts to HRK 960, i.e. equals 50\% of the total amount.

Chart I presents GMB amounts for type A and type B households together with the corresponding portions intended for children. The line named "Total - type A household ( 2 children)" shows that GMB amount for type A households falls uniformly from HRK I,6oo, when the net income is zero, all the way to HRK o when the net income amounts to HRK I,6oo. The line designated "For children - type A

\footnotetext{
${ }^{\mathrm{I}}$ These assumptions and terms were introduced for the sake of simplicity. The adult member might be a parent, adoptive parent, guardian, stepfather/stepmother, grandfather/grandmother or any other person supporting the children. Children may also be of preschool age, elementary school age, of secondary education age or higher education students. For details on the definitions of adults and children, see the Child Benefit Act, the Social Care Act and the Personal Income Tax Act.

${ }^{2}$ GMB was introduced in January 2014 as a replacement for social assistance. For more information on GMB, see Social Care Act and the information available on the website of the Ministry of Social Policy and Youth.
} 
households ( 2 children)" demonstrates that the children's portion (40\% of the total GMB amount) correspondingly falls from HRK 640 to HRK o.

\section{Ghart I}

Guaranteed minimum benefit, in dependence on net household income (in HRK)

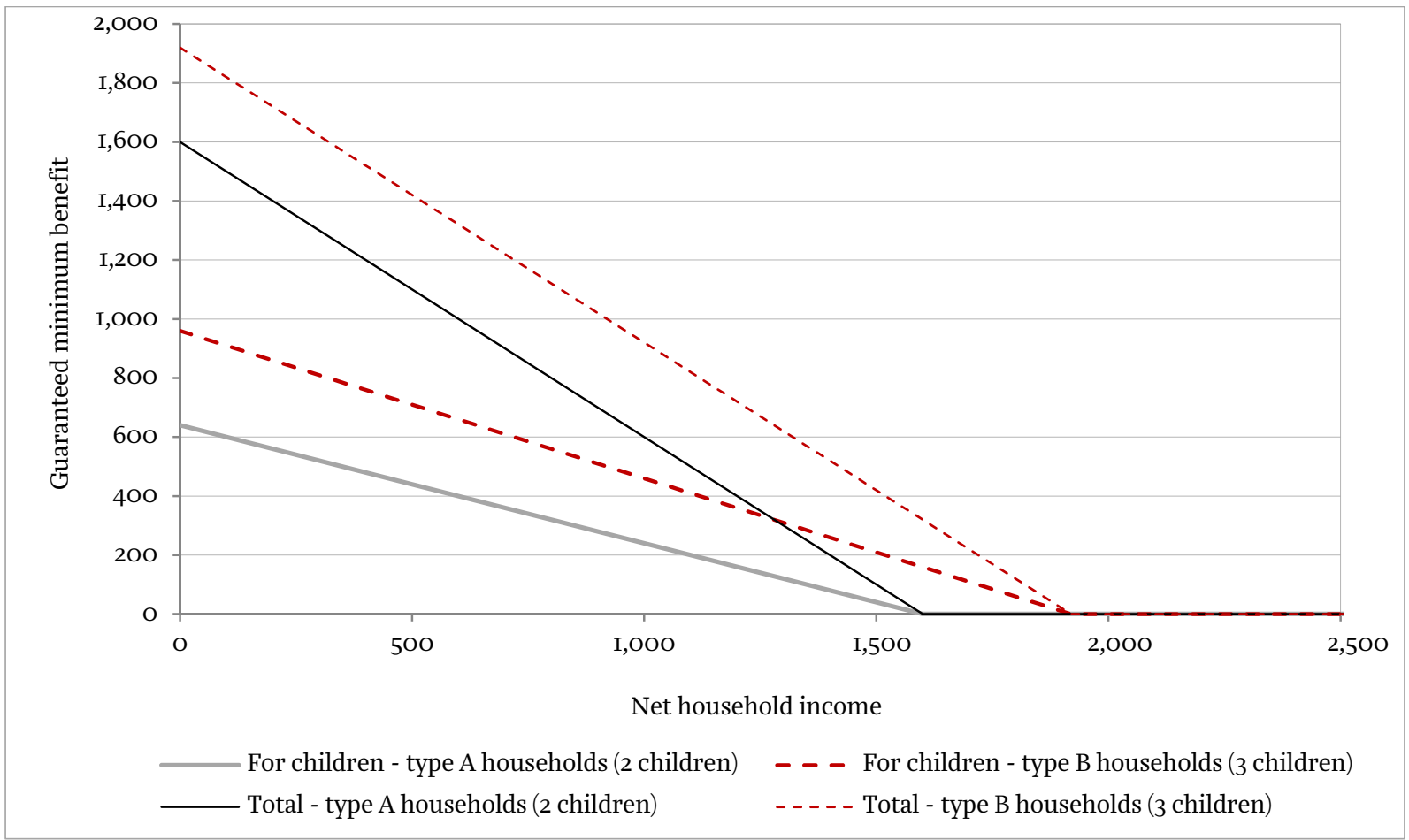

Source: author's calculation

A similar trend can be observed for type B households, where the portion intended for children (50\% of total GMB amount), designated by the line "For children - type B households (3 children)", drops from the maximum HRK 900 all the way to zero.

\section{CHILD BENEFIT}

Child benefit (CB) is a social and pronatality benefit intended for households with children that meet certain income criteria. Unlike GMB, CB does not also entail assets testing.

The CB comprises the "base portion" and the supplement for households with three or more children. ${ }^{3}$ The base portion is a product of the number of children and a certain amount which is dependent on the NIHM. As shown in Table 2, if NIHM is between HRK o and 543, the number of children is multiplied by [HRK] 299. ${ }^{4}$ If NIHM is between HRK 543 and I,I2O, the multiplication factor equals [HRK] 249; if NIHM falls in the range between HRK I,I2O and I,663, in order to calculate the CB, the number of children is multiplied by the $[\mathrm{HRK}] 200$.

If NIHM is below HRK I,663 and the household comprises three children, a bonus in the amount of HRK 500 is added to the base portion. Furthermore, provided that NIHM is still below HRK I,663, and that there are four or more children in the household, the bonus added to the base portion amounts to HRK

\footnotetext{
${ }^{3} \mathrm{CB}$ amount is additionally increased for children without one or both parents as well as for children with health disabilities. For more information on CB, see Child Benefit Act and information available on the Croatian Pension Insurance Institute website. ${ }^{4}$ All amounts are rounded for the sake of simplicity.
} 
I,Ooo. This bonus for households with three or more children is usually called the "pronatality supplement", although the Child Benefit Act itself does not provide a specific name for the bonus. ${ }^{5}$

Table 2

The base portion of the child benefit (in HRK)

\begin{tabular}{ccc}
$\frac{\text { NIHM }}{\text { O to } 543}$ & The base part of the CB \\
\hline 543 to I,I2O & 299 x number of children \\
\hline I,I2O to I,663 & 200 x number number of children \\
\hline Above I,663 & O \\
\hline
\end{tabular}

Source: author's calculation

As an example, a household comprising two adults and three children and having a total net income amounting to HRK 7,500 is analyzed. It follows that the NIHM equals HRK I,5OO, which places this example household in the HRK I,I2O to I,663 band. The base portion amounts to HRK 600 ( 3 x HRK 200), to which HRK 500 is added due to the fact that there are three children in the household. Therefore, the CB for this household amounts to HRK I,IOO, as seen in Table 3.

Table 3

Total child benefit

\begin{tabular}{|c|c|c|c|c|c|}
\hline \multirow{2}{*}{ NIHM (in HRK) } & \multicolumn{5}{|c|}{ Number of children } \\
\hline & $I$ & 2 & 3 & 4 & 5 \\
\hline o to 543 & 299 & 598 & I,397 & 2,196 & 2,495 \\
\hline 543 to I,I2O & 249 & 498 & $\mathrm{I}, 247$ & I,996 & 2,245 \\
\hline I,I2O to I,663 & 200 & 400 & I,IOO & $\mathrm{I}, 8 \mathrm{OOO}$ & 2,000 \\
\hline More than I,663 & $\mathrm{O}$ & $\mathrm{O}$ & $\mathrm{O}$ & $\mathrm{O}$ & $\mathrm{O}$ \\
\hline
\end{tabular}

Source: author's calculation

Chart 2 outlines CB dependence on household net income. Let us first review the CB for type A households (two adults with two children). If a household's net income is below HRK 2,I73, the CB amounts to HRK 6oo. Income between HRK 2,I73 and HRK 4,478 entitles a household to a CB amounting to HRK 50O, while the CB for households with a net income between HRK 4,478 and 6,652 equals HRK 400.

The CB function's graph is "stepwise", as can be observed in Chart 2. Mathematically speaking, this function is non-continuous, as it has points where the values change abruptly. Namely, if a family's income is just one HRK above a certain threshold value, the CB amount may drop by a hundred or more HRK. Taking as an example two type A households, AI, with a net income amounting to HRK 6,65I, and A2, with an income only HRK 2 higher, i.e. HRK 6,653, household As is eligible for the CB in the amount of HRK 4OO, while household A2 is ineligible for child benefit!

In situations such as these, "earning more" means "getting less" in the end, providing a stimulus to actually reduce one's income by a certain amount in order to obtain a higher child benefit and thus a greater disposable income. For example, a person in the A2 household might ask their employer for a HRK 5 lower income: this would make the household eligible for a CB in the amount of HRK 400 and produce a net gain of HRK 395. Furthermore, such a schedule violates the principle of horizontal equity, whereby similar households (as regards the structure and the level of income) should receive approximately equal benefits.

\footnotetext{
${ }^{5}$ Introduction of the "pronatality supplement" in early 2007 sparked an interesting debate on one Internet forum; some of the results of this analysis were heralded there.
} 


\section{Chart 2}

Child benefit's (CB) dependence on net household income (in HRK)

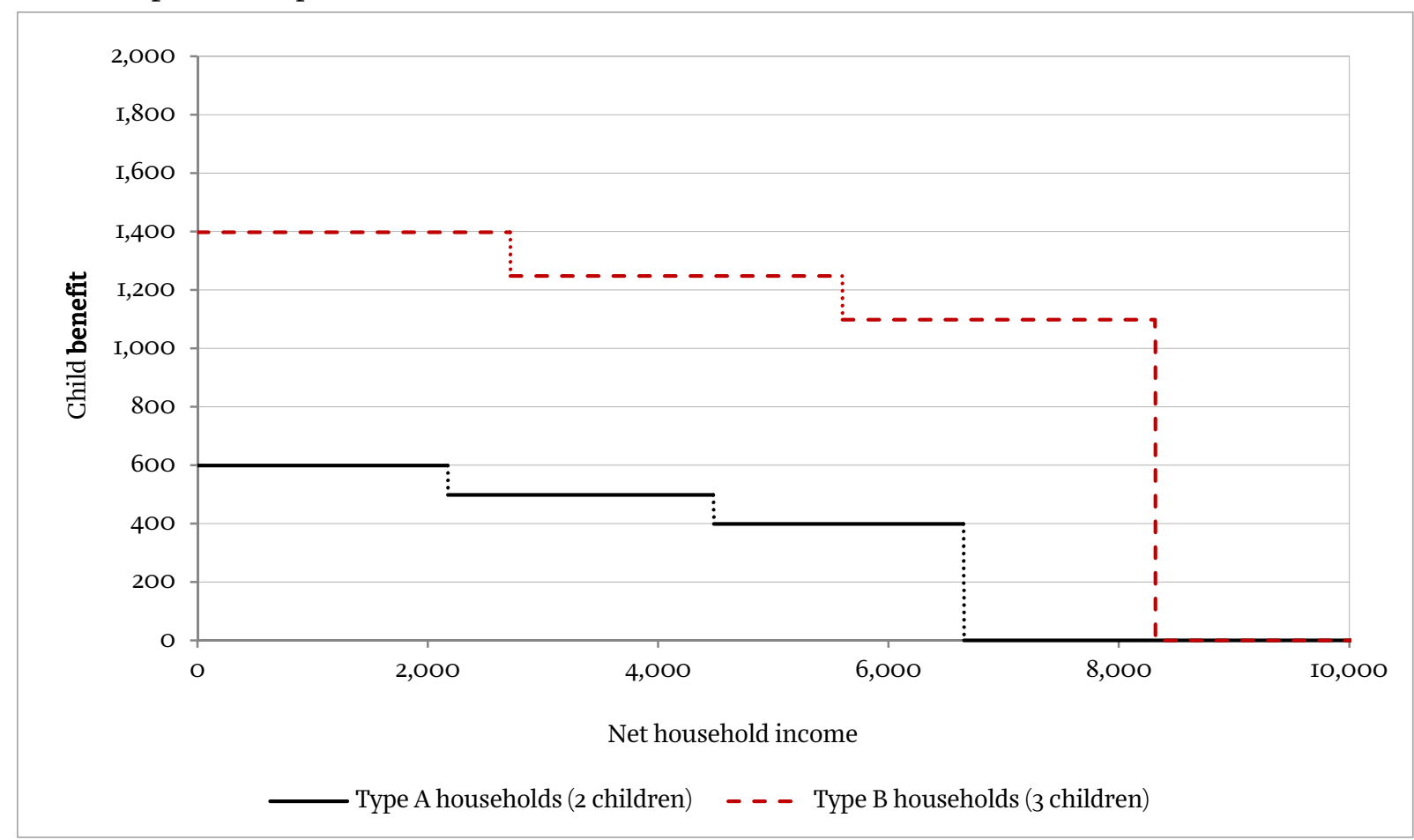

Source: author's calculation

The chart demonstrates that the function graph for type B households (two adults with three children) has a similar shape, albeit slightly"drawn out", as these households have 5 members, as opposed to type A households with 4 members. The amounts due to type B households are significantly higher as they are entitled to the "pronatality supplement". However, the sudden drops in the CB amounts are even more visible in this case. Taking as an example two households, BI and B2, with their net incomes amounting to HRK 8,3I4 and 8,3I6 respectively, BI household should receive CB amounting to HRK I,IOO, and B2 nothing at all.

\section{REDUCED PERSONAL INCOME TAX AND SURTAX DUE TO PERSONAL TAX ALLOWANGE FOR GHILDREN}

The third instrument under analysis in this paper is the reduction in the PIT and the surtax, as result of the personal tax allowance for children. ${ }^{6}$ Personal tax allowance for children is a tax relief which reduces the PIT base and which is available to all taxpayers supporting children. Monthly personal tax allowance for children amounts to HRK I,IOO for the first child, HRK I,54O for the second child, HRK 2,200 for the third child, etc. For example, as evidenced in Table 4, the monthly personal tax allowance amounts to HRK 2,640 for a family with two children, while the said allowance for a family with five children amounts to HRK I2,IOO.

\section{Table 4}

Personal tax allowance for children (in HRK) No. of children

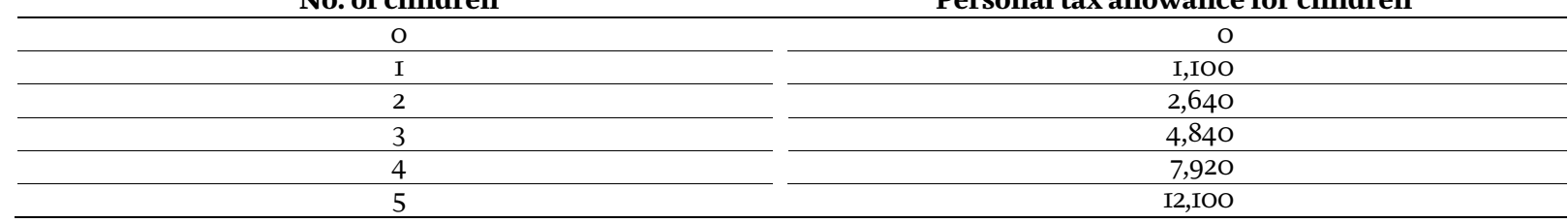

Source: author's calculation

${ }^{6}$ Only a selection of regulations concerning PIT is presented here. For more details, see Personal Income Tax Act and Tax Administration website. 
As stated above, those entitled to personal tax allowance for children are adults supporting children. In this analysis, they are two adult household members who share the personal tax allowance for children equally.? In type A households (two children), each adult shall therefore use a half of the HRK 2,640, i.e. HRK I,32O each. In type B households (three children), the adult members shall again divide the total amount (HRK 4,84O), thus each obtaining the right to a personal tax allowance for children of HRK 2,42O.

In addition, each adult member of the household, in their capacity as a taxpayer, is entitled to a basic personal tax allowance amounting to HRK 2,200. This means that the total personal tax allowance - sum of the basic personal tax allowance and the personal tax allowance for children - for each adult in type A household amounts to HRK 4,52O (2,200 + I,320 ) and to HRK 4,62O $(2,200+2,420)$ for each adult member in type B households.

Tax base is equal to pre-tax income reduced by the total personal tax allowance amount. As shown in table 5, the lower HRK 2,200 of the tax base is multiplied by the $12 \%$ rate. The next HRK 6,600 is multiplied by the $25 \%$ rate, while the portion of the tax base above 8,800 HRK is multiplied by the $40 \%$ rate. The sum of these three products of multiplication is added to form the PIT liability.

\section{Table 5}

Personal income tax base and rates

Monthly tax base (in HRK)

Rate (in percentages)

\begin{tabular}{cc}
\hline between HRK O and 2,20O & I2 \\
\hline between HRK 2,200 and 8,800 & 25 \\
\hline above HRK 8,800 & 40 \\
\hline
\end{tabular}

Source: author's calculation

How is PIT liability influenced by the increase in personal tax allowance, i.e. the reduction in the tax base? Let us take taxpayers $\mathrm{V}$ and $\mathrm{Z}$ as an example, with pre-tax incomes amounting to HRK 6,000 and 20,00O, respectively, having an equal personal tax allowance amounting to HRK 5,00O. Their respective tax bases are HRK I,OOO and 15,00O. PIT for person V equals I,OOO x 0.I2 = HRK I2O. PIT for person Z equals 2,200 × $0.12+6,600 \times 0.25+6,200$ x $0.4=$ HRK 4,394.

Let us imagine that both taxpayers' bases are reduced by HRK Ioo, the new amounts being HRK 9oo for person V and HRK I4,900 for person Z. Person V's PIT now amounts to HRK IO8, thus a reduction of only HRK I2. Person Z's tax now amounts to 2,200 x 0.12 + 6,600 x 0.25 + 6,IOO x 0.4 = HRK 4,354, only HRK 40 less than the original amount. The only amount changed in the calculation was the one multiplied by the $40 \%$ rate, which tells us that the reduction of the tax base affected only the uppermost part of the base, the one multiplied by the $40 \%$ rate. Therein lies the conclusion of this example: the key tax rate affected by the change in personal tax allowance is the highest threshold rate applicable to a specific taxpayer. For person $\mathrm{V}$ that rate is $\mathrm{I} 2 \%$; for person $\mathrm{Z}$ the affected rate is $40 \%$.

Finally, the surtax is calculated by multiplying the surtax rate by the PIT liability. The example surtax rate applied in this paper is $12 \%{ }^{8}$

Chart 3 presents PIT and surtax reductions for type A and B households provided by the personal tax allowance for children for a wide range of net household incomes, from zero to HRK 30,000. For households whose net income is below HRK 4,80o, there is almost no saving, as taxpayers with such low

\footnotetext{
7 In this model, both adults have the same pre-tax income, which makes it optimal for the household to split the personal tax allowance for children in two equal parts. However, other patterns in dividing the allowance are possible, depending on the income levels. For example, if one parent earns significantly more than the other, it might be optimal for the higher earning parent to use the full amount of the personal tax allowance for children.

${ }^{8}$ Surtax rate is determined by cities and municipalities, within a defined framework. See Tax Administration website.
} 
income do not fully use even their basic personal tax allowance. ${ }^{9}$ In the net income range from HRK 4,800 to 7,04O, the saving increases to HRK 355 equally for type A and type B households. Above HRK 7,040, the saving continues to rise for both types of households, albeit more rapidly for type B households due to their higher personal tax allowance for children. The saving is capped at HRK I,I83 and HRK 2,I68, for type A and type B households respectively.

\section{Chart 3}

Reduction in income tax and surtax due to personal tax allowance for children (in HRK)

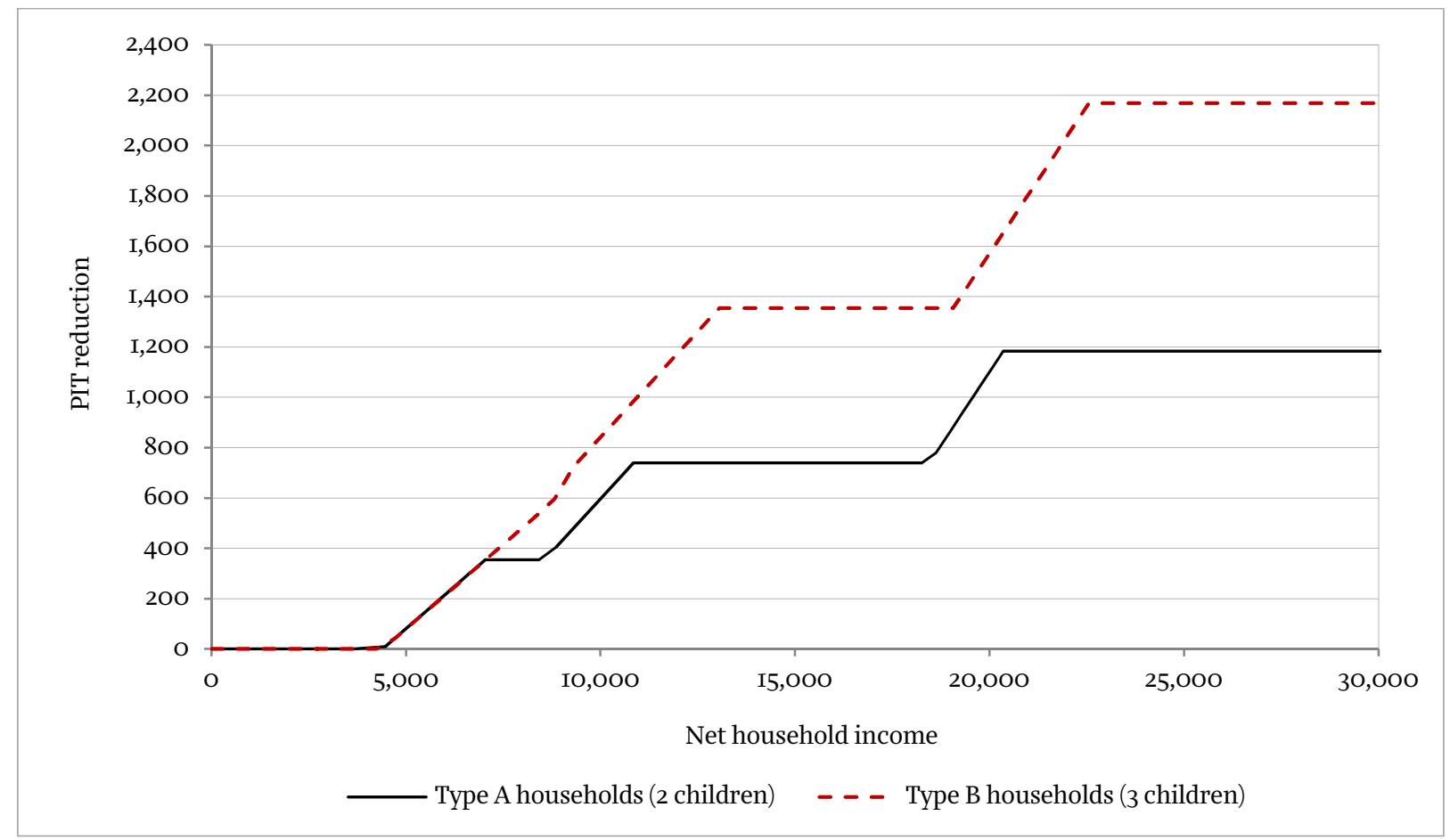

Source: author's calculation

This type of support also demonstrates stepwise changes in the amounts. For example, in type A households, for a household with a net income of HRK 8,425, the support amounts to HRK 355, while for a household with a net income of HRK IO,850, the support amounts to HRK 740 . Thus a $28 \%$ increase in income leads to a I08\% increase in the amount of support. The abrupt rise in the support amount is due to entering a higher tax band which is subject to a higher threshold rate.

\section{OVERALL SUPPORT FOR GHILDREN}

Using information presented in previous charts, the amounts of the three supports are added in order to obtain the overall support for children. The result of performing this addition for all net household income levels is presented in Chart 4. Graphs of overall support for children for type A and type B households have similar shapes.

Let us first look at the graph representing type A households. If a household's net income equals zero, the overall support amounts to HRK I,24O; this is followed by a steep drop - due to the nature of GMB and CB - so that the overall support amount for a net household income of HRK 2,200 equals HRK 500. At the net income level of HRK 4,500, the overall support drops further, to HRK 400; after this point, the overall support begins to rise again all the way to HRK 7OO, as the personal tax allowance for children kicks in. However, at the income level of HRK 6,653, another drop - to HRK 300 - can be observed, this

9 Total household income in the amount of HRK 4,80O corresponds to two salaries in the amount of HRK 2,400 (after deducting social security contributions). By deducting the basic personal tax allowance (HRK 2,200), one obtains a tax base in the amount of HRK 200 which is then taxed with the I2\% rate. Thus, PIT with surtax for a single taxpayer is HRK 27, i.e. HRK 54 for the couple. 
time due to the sudden disappearance of CB. Afterwards, at the income level of HRK 8,500 and above, the overall support starts to rise again due to the personal tax allowance for children, an effect already observed in Chart 3.

\section{Chart 4}

Overall support for children (in HRK)

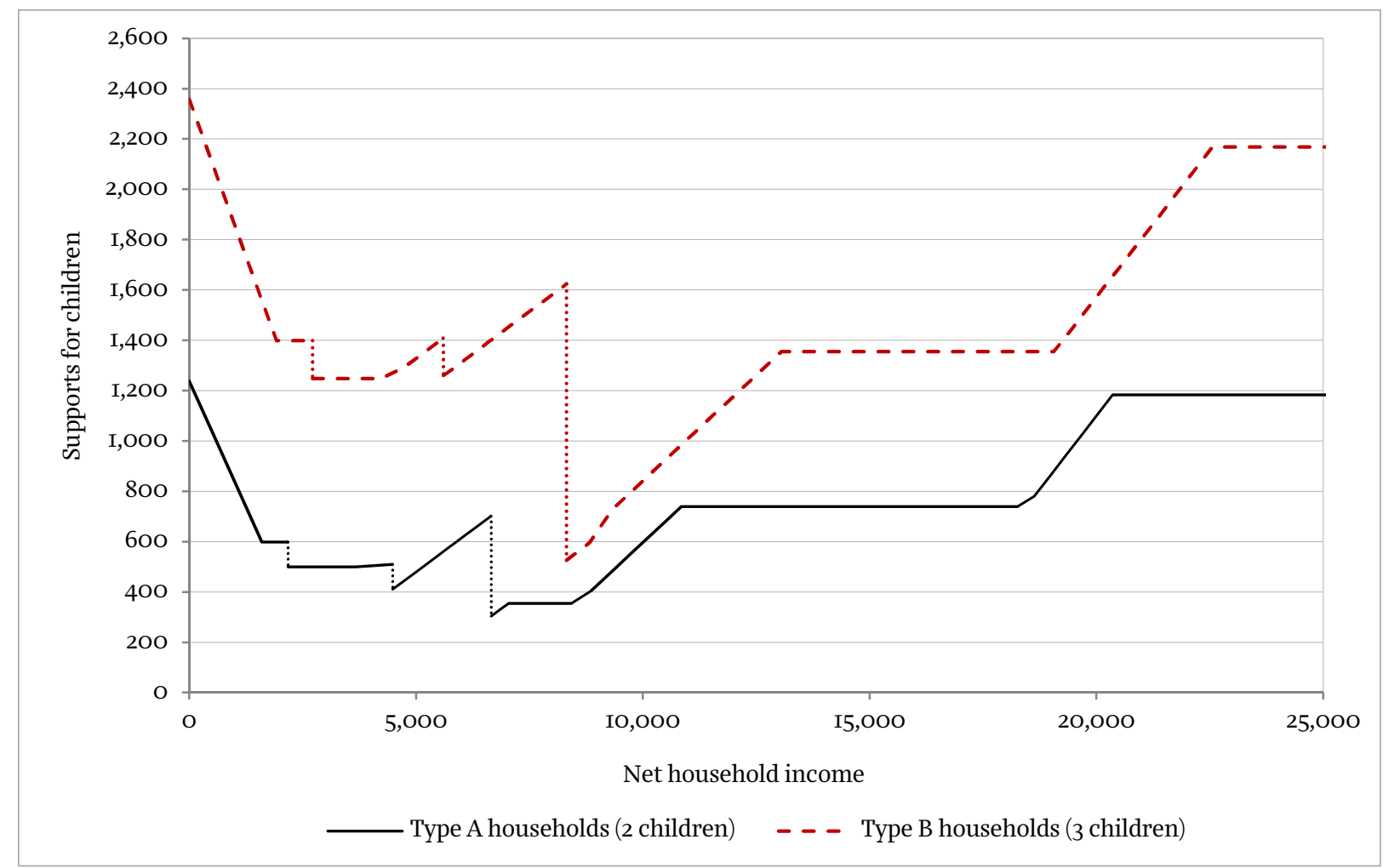

Source: author's calculation

Almost the same pattern can be observed in type B households, albeit with a much more pronounced drop in overall support at the point of CB disappearance at the net income level of HRK 8,316 - from HRK I,625 to 526, i.e. a drop of HRK I,099.

It is interesting to observe the difference in overall support for type A and type B households, which might be named as the "third child incentive." The amount of this incentive varies greatly. At the HRK o net income level, the "incentive" amounts to HRK I,I2O; it then drops to HRK 700 at the net income level of HRK 6,653. In the net income range between HRK 6,700 and 8,315, the incentive amount ranges between HRK I,IOO and HRK I,3OO. In the wide interval between net incomes of HRK 8,316 and HRK IO,850, it amounts to only HRK 200. Above this range, it rises again.

\section{DISPOSABLE HOUSEHOLD INCOME}

Chart 5 demonstrates the interdependence between pre-tax income and disposable income. At several points, it can be seen that function graphs are not smooth which is, as stated before, a result of CB's stepwise design. Let us look at two hypothetical type B households, B3 with a pre-tax income amounting to HRK 8,3I4 and B4 with a pre-tax income amounting to HRK 9,44O. Although household B4 earned HRK I,I26 more in the market, both households have an equal net income amounting to HRK 9,4I3. 


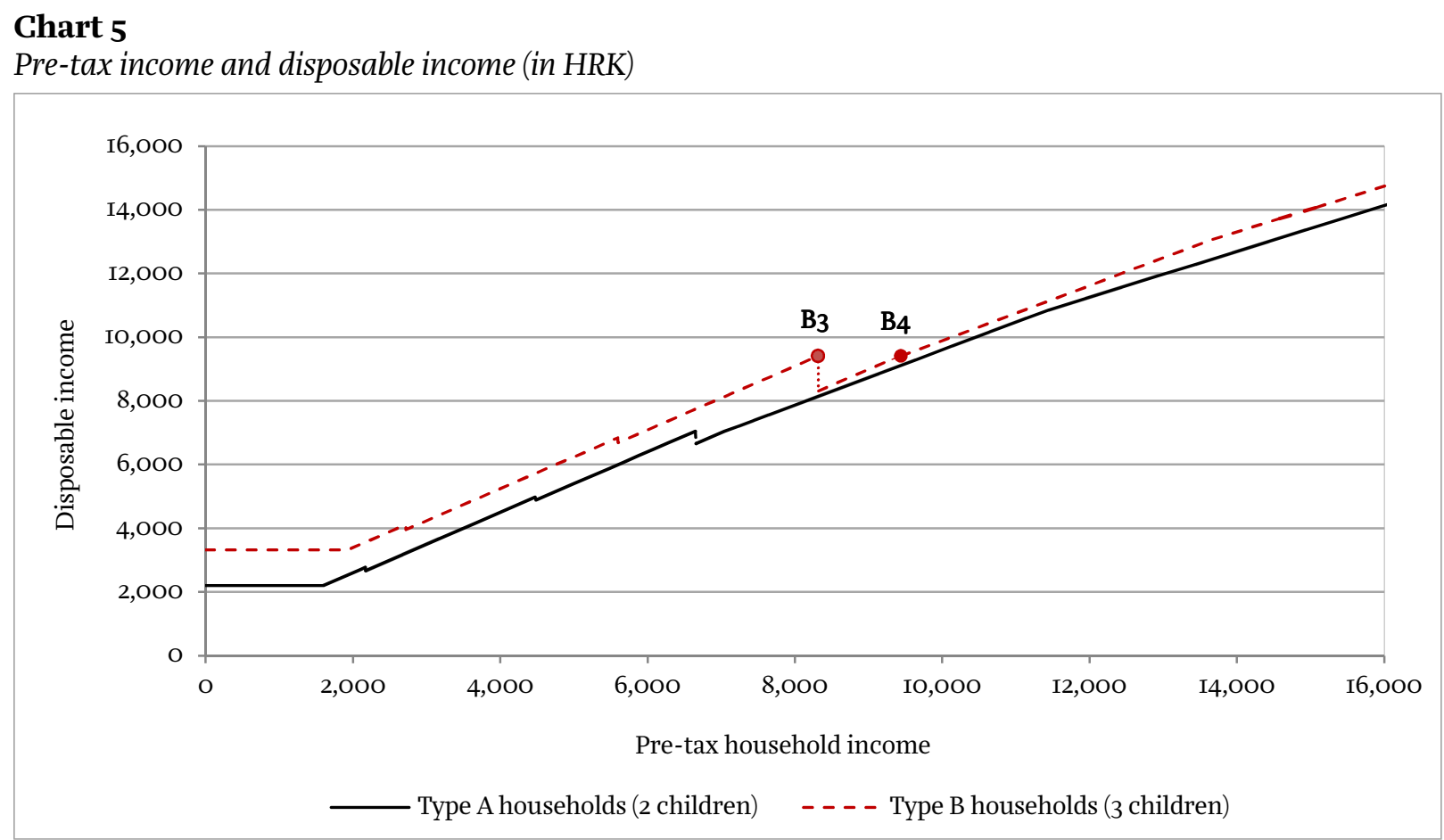

Source: author's calculation

\section{OVERALL SUPPORT "FUNCTION SMOOTHING"}

In order to remove the areas of horizontal inequity, is there a way to smooth over the breaks and irregularities in the overall support function (Chart 4)? Can the "third child incentive" be made equal for households at different income levels?

As an illustration, this paper offers a simulation of a system reform that might resolve the above mentioned issues. By way of this reform, one should simultaneously: (a) change the child benefit in such a way that its amount is not dependent on income level; (b) abolish personal tax allowance for children; (c) lower the $25 \%$ threshold tax rate to $24 \%$, and the $40 \%$ rate to $36 \%$. The GMB remains unchanged in this scenario.

In this simulated system, all households with an equal number of children would receive the same CB amount, notwithstanding net income differences. In this way, all type A households (with two children) would receive the CB in the amount of HRK 600 while all type $B$ households (with three children) would receive HRK I,40O. ${ }^{\text {IO }}$ Households with lowest incomes would continue to receive the GMB portion intended for children. Being that there would be no personal tax allowance for children, supports for children would consist of the GMB portion intended for children and the CB.

Chart 6 presents a comparison of the overall support function graphs for the current and the simulated system. In the simulated system, type A households with zero income receive overall support for children amounting to HRK I,24O (CB in the amount of HRK 600 and the portion of GMB intended for children in the amount of HRK 640). Type B households with zero net income receive HRK 2,360 (CB in the amount of HRK I,4OO and the portion of GMB intended for children in the amount of HRK 960). From this point, overall support gradually declines as the GMB portion intended for children is reduced; the GMB portion intended for children drops to zero at the net household income levels of HRK I,60O and HRK I,920, for type A and type B households respectively. In short, the simulated and the existing systems are identical as regards the lowest income households.

Io These amounts (HRK 600 and HRK I,40O) were chosen in order to approximately match the average amount of overall support for children (excluding MGB). 
All type A households with a net income above HRK I,6oo receive the same amount of overall support for children (HRK 6oo); all type B households with a net income above HRK I,92O also receive the same amount, HRK I,4OO. In the simulated system, there are no sudden jumps in the overall support graph functions. Furthermore, the difference in the amounts received between type A and type B households, i.e. the "the third child incentive", does not change for different net incomes.

\section{Chart 6}

Overall support for children in existing and simulated systems (in HRK)

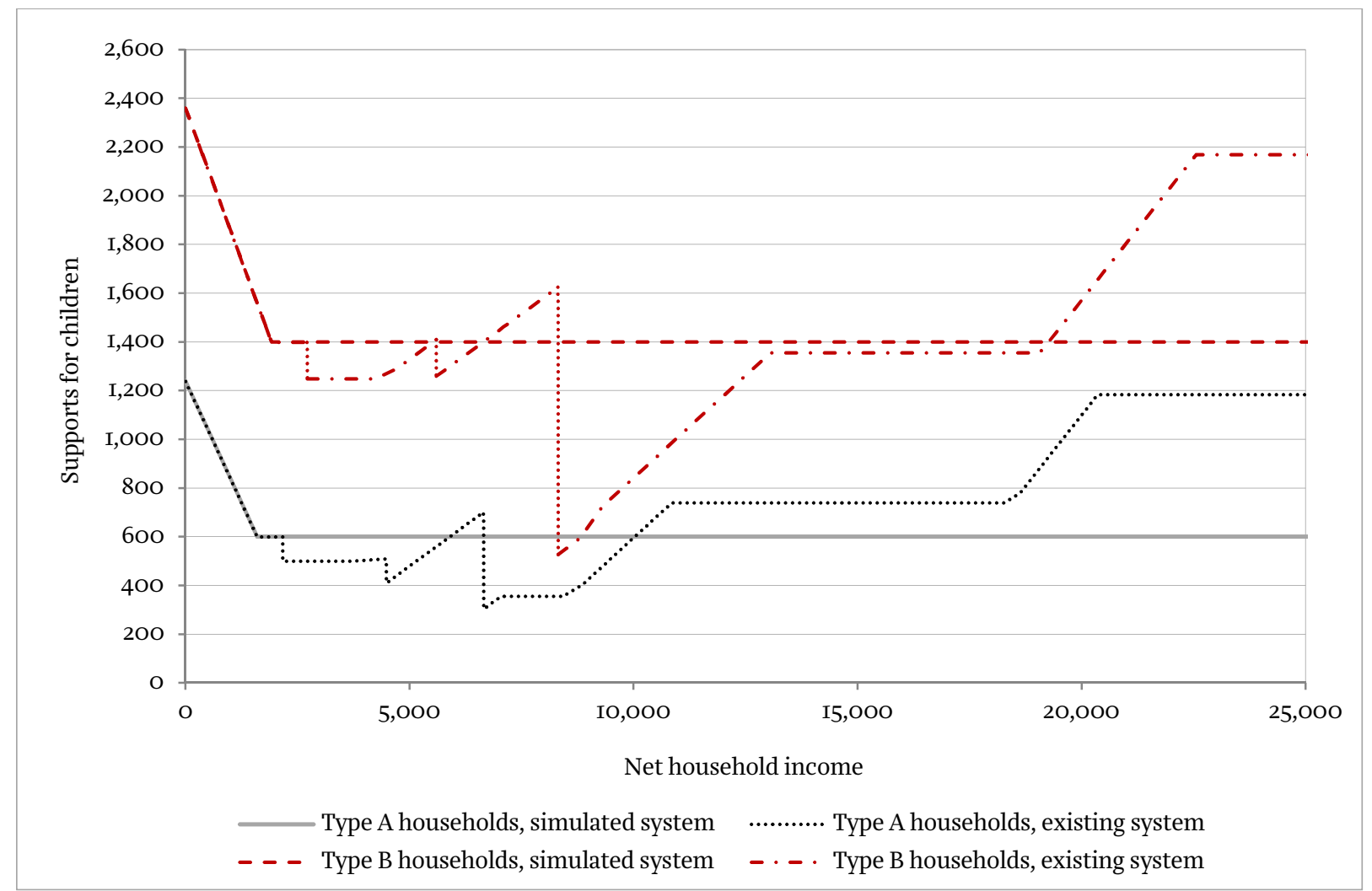

Source: author's calculation

In the simulated system, graphs for the disposable income function are smoothed as well, as shown in Chart 7 which compares the simulated and the existing systems. The "winners" in the simulated system are type A households with a pre-tax income between HRK 6,656 and Io,640 as well as type B household with a net income in the range between HRK 8,316 and 13,500.

It would appear that the "losers" in the simulated system are those households with a net income higher than HRK 20,000. As stated before, type A households with a net income above HRK 20,350 are currently receiving the support for children of HRK I,I83, while type B households with a net income above HRK 22,500 are receiving HRK 2,I68. By abolishing personal tax allowance for children and changing CB, overall support payments drop by HRK 583 for such type A households and by HRK 768 for such type B households. However, such a loss is compensated by lowering threshold tax rates in the PIT. 


\section{Chart 7}

Pre-tax income and disposable income in existing and simulated systems (in HRK)

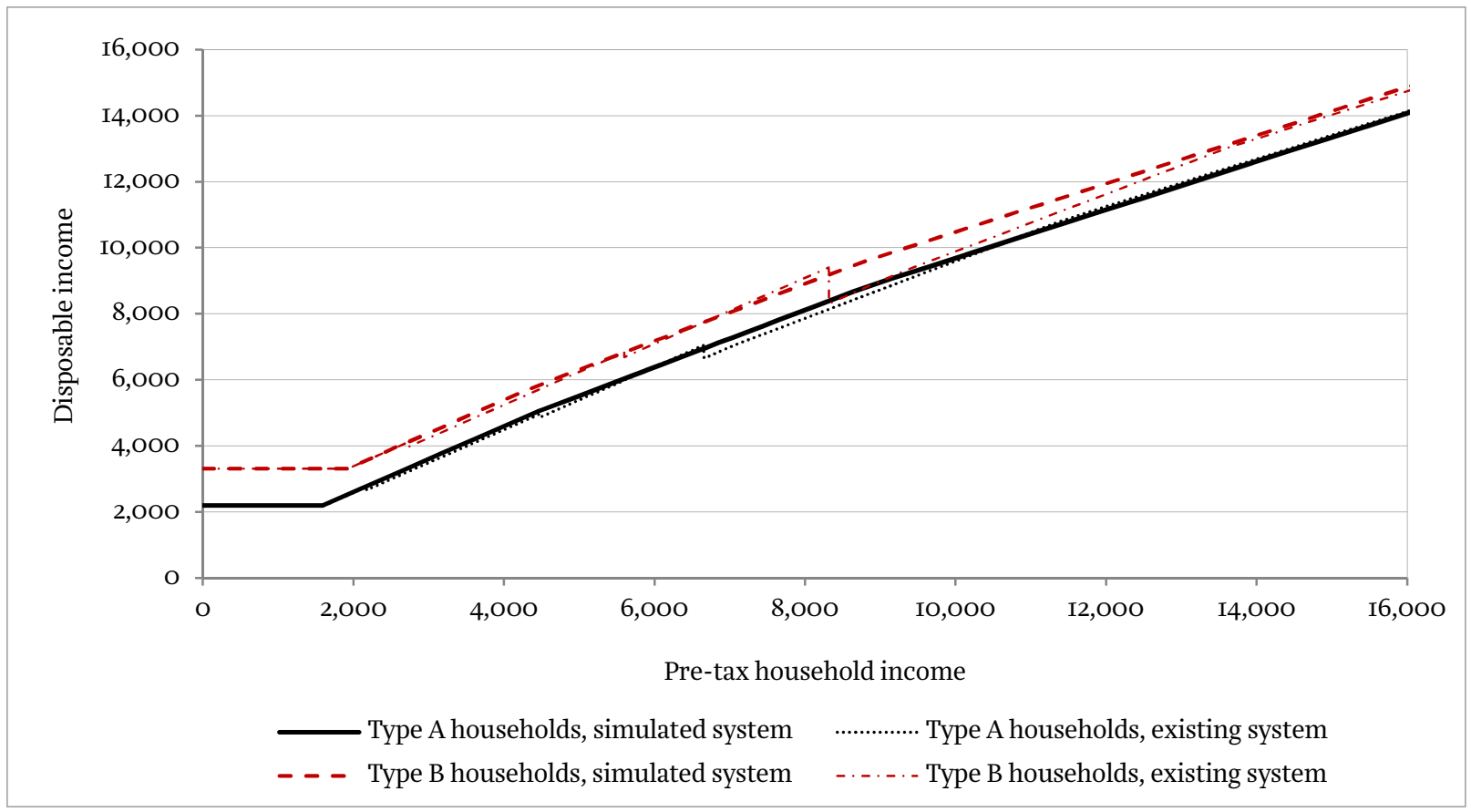

Source: author's calculation

\section{GONCLUSION}

In this paper, we analyzed how the budgets of households with children are influenced by three tax and social policy instruments: child benefit, guaranteed minimum benefit and personal tax allowance for children. The amounts households receive on the basis of these benefits and tax reliefs were named supports for children. Graphs of functions were plotted for individual supports as well as for overall support for children, describing their dependency on net household income.

The key problem of this set of supports for children lies with the "stepwise" design of the child benefit which leads to small changes in income levels resulting in large changes in the benefit amounts received. The most remarkable example is given by comparing two households comprising two adults and three children. Net income for the first household is HRK 8,314; for the second, net income is HRK 8,3I6. Child benefit for the first household amounts to HRK I,IOO; for the second, it equals zero. Such sudden changes are also present, although to a lesser degree, in the personal tax allowance for children.

Households with children, at all income levels, receive a certain amount of supports for children. These amounts vary significantly depending on the net income level. For a household with two children, overall support for children ranges from HRK 300 (if the net household income amounts to HRK 6,652) all the way to HRK I,200 (if the net household income is either HRK o or higher than HRK 20,000). For a household with three children, overall support for children ranges from HRK 526 (if the net household income amounts to HRK 8,316) all the way to HRK 2,000 and more (if the net household income is either HRK o or higher than HRK 22,500).

The difference in overall support for children between households including two or three children respectively and having the same income is called the "third child incentive". This incentive is highly variable at different net income levels and ranges from only HRK 200 in the interval between HRK 8,316 and HRK IO,850 all the way to HRK I,300 in the case of an income amounting to HRK 8,3I4. 
The presented charts may lead to various conclusions and suggestions concerning the design and the amount of guaranteed minimum benefit, child benefit and PIT. What can assuredly be said at this point is that graphs for the supports' functions need to be "smoothed", i.e. stepwise changes in their amounts need to be diminished. For this reason, an example simulation of a simple reform was presented, whereby negative incentives and horizontal inequities are removed and the amount of the "third child incentive" is standardized.

When reforming the system, it is paramount to avoid partial and ad hoc solutions. For this reason, charts, similar to those presented in this paper, should be plotted for other types of households, such as, for example, for single-parent households. Scenarios dealing with households with newly born children should also include maternity, parental and other benefits. For a simulation of the real effects of tax and social benefits reform on citizens' standard of living and state budget, microsimulation models, such as miCROmod ${ }^{\mathrm{II}}$, need to be applied.

\section{REFERENCES}

Zakon o doplatku za djecu, NN 94/OI, I38/o6, IO7/O7, 37/O8, 6I/II, II2/I2.

Zakon o porezu na dohodak NN I77/O4, 73/o8, 8O/IO, II4/II, 22/I2, I44/I2, 43/I3, I2O/I3, I25/I3, I48/I3

Zakon o socijalnoj skrbi, NN I57/I3/I2, 43/13, I2O/I3, I25/I3, I48/I3.

"I For more information on miCROmod, see Institute of Public Finance's website. 